\title{
Formulation of somatostatin analog tablets using quality by design approach
}

\section{Zoya Shprakh ${ }^{1,2}$}

${ }^{1 " N . N . ~ B l o k h i n ~ N a t i o n a l ~ M e d i c a l ~ R e s e a r c h ~ C e n t e r ~ o f ~ O n c o l o g y " ~ o f ~ t h e ~ M i n i s t r y ~ o f ~ H e a l t h ~ o f ~ t h e ~ R u s s i a n ~ F e d e r a t i o n ~(N N ~ B l o k h i n ~ N M R C O), ~ M o s c o w, ~ R u s s i a . ~}$ ${ }^{2}$ I.M. Sechenov First Moscow State Medical University of the Ministry of Health of the Russian Federation (Sechenov University), Moscow, Russia.

\begin{tabular}{l}
\hline ARTICLE INFO \\
\hline Received on: 29/11/2020 \\
Accepted on: 11/02/2021 \\
Available online: 05/04/2021 \\
\\
\hline Key words: \\
Somatostatin analog, quality \\
by design, quality target \\
product profile, critical \\
quality attributes, risk \\
assessment, tablet.
\end{tabular}

\begin{abstract}
The primary purpose of the present study was to apply the quality by design approach to the formulation of the somatostatin analog (SSA) cyphetrylin dosage form. Experimental investigations of cyphetrylin activity in vivo showed that its oral administration is optimal. For better patient compliance and product quality, an interdisciplinary team identified the quality target product profile and determined the critical quality attributes (CQAs) related to product safety and efficacy. On the basis of our own in vitro/in vivo nonclinical data and experience of SSA medicinal use, we estimated the criticality of each CQA by a specially created scale. Because of the minimal quantity of the active substance in the tablet, the assay and uniformity of content are defined as the most CQAs. Estimation of the manufacturing process by methods of the risk analysis and mitigation matrix and failure mode effect analysis allowed us to determine the effects of process unit operations on final product in-process CQAs and to characterize the granulation and compression as the most critical steps. It has been shown that the moisture content of granulate is the most significant in-process CQA, which affects the disintegration and resistance to crushing of tablets and their microbial limits.
\end{abstract}

\section{INTRODUCTION}

Neuroendocrine tumors (NETs) are rare human tumors, but in the last 30 years the incidence of this disease has increased 6.4 times and has become 6.98 patients for 100,000 citizens (Dasari et al., 2017).

The unique role in the NET treatment play somatostatin analogs (SSAs). SSAs have antitumor activity and at the same time may be very effective for specific carcinoid syndrome control Now SSAs are the standard therapy for functional NET treatment (Bousquet et al., 2012; Oberg et al., 2014; Yao et al., 2013).

The most widely used products of this group are Octreotide, Lanreotide, and Pasireotide, which are manufactured in the form of solutions for subcutaneous or intramuscular injections or in dosage forms with the prolonged release, microspheres, and

"Corresponding Author

Zoya Shprakh, "N.N. Blokhin National Medical Research Center of Oncology" of the Ministry of Health of the Russian Federation (N.N. Blokhin NMRCO), Moscow, Russia; I.M. Sechenov First Moscow State Medical University of the Ministry of Health of the Russian Federation (Sechenov University), Moscow, Russia.E-mail: z.shprakh@ronc.ru biodegradable liquid-crystalline gel (Anthony and Freda, 2009; Gobeaux et al., 2012; Tiberg et al.,2015).

Many investigators tried to increase SSA enteral absorption to create dosage forms for oral administration, but neither of them was commercially successful (Thanou et al., 2001).

The development and use of SSAs for oral administration are limited by the physical and chemical properties of active substances; the molecules are big with a significant tendency to aggregation, absorption, and denaturation (Bak et al., 2015; Shaji and Patole, 2008).

Besides the possibility of fermentative degradation in the gastrointestinal tract, failure to cross through an intestine epithelial barrier, and short half time in blood plasma lead to a low and variable system bioavailability of SSAs for oral administration (Thundimadathil, 2012).

Several SSAs have been synthesized in N.N. Blokhin National Medicinal Research Center of Oncology of the Ministry of Health of the Russian Federation (N.N. Blokhin NMRCO), including cytotoxic SSAs. Their antitumor effect has been studied in the experiments in vitro and in vivo (Borisova et al., 2017; Osipov et al., 2016). 
One substance was estimated as the most effective (Mikhaevich et al., 2013). It is a pentapeptide (Boc-Cys(Thp)Phe-D-Trp-Lys(Z)-Thr-OMe) with a noncyclic structure and was named cyphetrylin. Cyphetrylin is insoluble in water and is metabolically stable in the gastric fluid because of reactive group blocking (Shprakh et al., 2014).

The purpose of the present study is to apply elements of quality by design (QbD) approach in the pharmaceutical development of cyphetrylin dosage form.

\section{MATERIALS AND METHODS}

\section{Chemicals and reagents}

Cyphetrylin active pharmaceutical ingredient (API) was obtained from the chemical synthesis laboratory of N.N. Blokhin NMRCO (Smirnova et al., 2005).

To prepare cyphetrylin tablets, excipients - potato starch, lactose monohydrate, povidone, talc, microcrystalline cellulose, calcium stearate, and magnesium stearate-were purchased from different suppliers and conformed to PhEur requirements (European Pharmacopoeia 9.0., 2017). All other used chemicals and solvents were of analytical grade.

\section{Laboratory animals}

To determine the optimal route of cyphetrylin administration, we used 86 female mice CBA, 20-25 g). Mice were housed in group polypropylene cages in standard laboratory conditions (temperature $22^{\circ} \mathrm{C}-24^{\circ} \mathrm{C}$, humidity $45 \%-55 \%$, and 12-hours light/dark cycle) in the Experimental Biological Laboratory. Mice were acclimatized for 7 days before the experiment. During acclimatization and investigation, animals were given a standard mice pellet diet and mineral water ad libitum (Directive 2004/9/EC, 2004).

\section{METHODS}

\section{Research of optimal route of cyphetrylin administration}

Experimental animals were divided into groups: ten mice in control groups (did not receive investigated substance) and seven mice in treated groups. The mice in the treated groups received cyphetrylin in different dosage form models, finedispersed emulsion, liposomal dispersion, and suspension in the starch paste. Samples of the tumor tissue were prepared by standard method and injected subcutaneously into the right axillary zone of experimental animals. Animals received the models of cyphetrylin dosage forms intraperitoneally, intravenously, and per os in doses of 30,50 , and $70 \mathrm{mg} / \mathrm{kg}, 20$ and $40 \mathrm{mg} / \mathrm{kg}$, and 1,10 , and $50 \mathrm{mg} /$ $\mathrm{kg}$, respectively. The Research Ethics Committee of N.N. Blokhin NMRCO approved the research protocol.

\section{Cyphetrylin tablets preparation}

Cyphetrylin tablets were obtained by the wet granulation method (Shprakh et al., 2019a). Active substance and excipients (for 100 tablets) were blended, and the mixture was granulated using $5 \%$ starch paste as a binding agent and dried to complete drying out in granulator ROTO CUBE12 (IMA, Italy). After drying, the granulate was milled, and lubrication powder mixture (magnesium stearate, talc, and starch) was added to the blend. Tablets were compressed on eccentric tablet press Erweka (Germany) using 6 $\mathrm{mm}$, round, flat, and plain punches. The compressing machine was adjusted so that the manufactured tablets had an average weight of $\sim 105 \mathrm{mg}$ and a crushing strength not less than $30 \mathrm{~kg} \cdot \mathrm{m} \cdot \mathrm{s}^{-2}$.

\section{Cyphetrylin tablets characterization}

Test of loss on drying (moisture content) and flowability of granulate and control of cyphetrylin tablets disintegration, resistance to crushing, and microbial limits were carried out according to PhEur procedures (European Pharmacopoeia 9.0., 2017).

Cyphetrylin assay in tablets and uniformity of drug content was estimated using UV-spectrophotometry analytical method, described in (Shprakh et al., 2016). The specially synthesized cyphetrylin substance of $99.0 \%$ of the active ingredient was used as a standard sample. About $100 \mathrm{mg}$ of cyphetrylin rubbed tablets was dissolved in $50 \mathrm{ml}$ of ethanol $(0.12 \mathrm{mg} / \mathrm{ml})$ and filtered via Millipore with pore size $0.45 \mu \mathrm{m}$. The absorbance of this solution was measured at the maximum wavelength of cyphetrylin at $282 \pm 2 \mathrm{~nm}$. The absorbance of the cyphetrylin standard spirituous solution of the same concentration was measured in parallel. Cyphetrylin quantity calculation was carried out by a formula taking into consideration dilutions of all solutions and cyphetrylin content in substance.

The uniformity of drug content determination was performed for ten tablets separately described for assay test. 25 $\mathrm{ml}$ of $95 \%$ ethyl alcohol was added to each tablet and shaken intensively during 8-10 minutes. The liquid was filtered, and the drug content was determined after appropriate dilution with $95 \%$ ethyl alcohol.

For compatibility study, we estimated the level of related substances in cyphetrylin tablets at accelerated stability studies, using the high-performance liquid chromatography method.

To prepare test solution, the tablet was placed into the vial for autoinjector, $3 \mathrm{ml}$ of mobile phase was added and shaken intensively for 2 minutes, obtained suspension was centrifuged for 2 minutes with $2,000 \mathrm{rpm}, 200 \mu \mathrm{l}$ of supernatant was transferred into the headspace vial, and $600 \mu \mathrm{l}$ of mobile phase was added and mixed.

Chromatographic conditions: column YMC-PACK $\mathrm{SiO}_{2}$ $5 \mu \mathrm{m}, 3 \times 150 \mathrm{~mm}$, eluent flow rate $0,4 \mathrm{ml} / \mathrm{minutes}$, injection volume $5 \mu \mathrm{l}$, UV-detector $(\lambda=290 \pm 4 \mathrm{~nm})$. The mixture of $230 \mathrm{ml}$ of heptane, $210 \mathrm{ml}$ of chloroform, and $22 \mathrm{ml}$ of methanol was used as the mobile phase in the isocratic regimen.

Cyphetrylin retention time is about 4.5-4.7 minutes. Acceptance criteria of system suitability acceptance criteria were as follows: the resolution between the peak of cyphetrylin and impurity with relative retention time about 0.86 was no less than 2 , the relative standard deviation of cyphetrylin peak area response of 6 replicate injections was not more than $2.0 \%$, and the cyphetrylin pick tailing factor was not more than 1.3.

To study compatibility, we also analyzed the UVspectra of solutions of API, excipients, and mixture of API and excipients. For this, $0.006 \%$ spirituous solution of cyphetrylin was prepared: about $6 \mathrm{mg}$ of API (precisely weighed) was dissolved in $100 \mathrm{ml}$ of $95 \%$ ethyl alcohol and filtered via Millipore with pore size $0.45 \mu \mathrm{m}$. To obtain the solution of excipients, $550 \mathrm{mg}$ of lactose monohydrate, $50 \mathrm{mg}$ of microcrystalline cellulose, 250 $\mathrm{mg}$ of starch, $50 \mathrm{mg}$ of povidone, and $100 \mathrm{mg}$ of powder blend 
(magnesium stearate, talc, and starch) were mixed in the porcelain jar up to homogenous mass. About $100 \mathrm{mg}$ of the obtained mixture was transferred into $100 \mathrm{ml}$ measuring flask, dissolved in $95 \%$ ethyl alcohol, mixed, and filtered. The solution of API and excipients was prepared as follows: about $100 \mathrm{mg}$ of excipients and $6 \mathrm{mg}$ of cyphetrylin were mixed and transferred into $100 \mathrm{ml}$ measuring flask, dissolved in 95\% ethyl alcohol, mixed, and filtered.

Accelerated stability studies were carried out to confirm the absence of chemical interaction between API and excipients. The tablets were kept at $40^{\circ} \pm 2{ }^{\circ} \mathrm{C}$, in airtight high-density polyethylene bottles for 3 months, at $\mathrm{RH} 75 \% \pm 5 \%$, and the evaluation was carried out in each month.

For Initial Risk Assessment, we used the method of risk analysis and mitigation matrix (RAMM) (Brindle et al., 2012) and failure mode effect analysis (FMEA) (Inoue and Yamada, 2010).

\section{RESULTS AND DISCUSSION}

Cyphetrylin is methyl ether of $\mathrm{N}^{\alpha}$-tret-butyloxycarbonyl$\mathrm{S}$-tetrahydropiranylcystei-nylphenylalanyl-D-tryptophyl- $\mathrm{N}^{\varepsilon}$ carbobenzoxylysylthreonine. It is a pentapeptide, the analog of hypothalamic hormone somatostatin. Cyphetrylin is a white to yellowish powder; it is practically insoluble in water and slightly soluble in ethyl alcohol. The specialty of this molecule is its chemical and enzymatic stability due to the protection of the reactive side-chain groups with tretbutyloxycarbonylic, benzyloxycarbonylic, and tetrahydropyralic groups.

As far as SSA, cyphetrylin realizes direct antitumor action through binding with somatostatin receptors (SSTR). Most of SSTR is expressed in neuroendocrine tumor cells (Shprakh, 2020) and the tissues of the stomach and intestine (Gugger et al., 2004). Studies of cyphetrylin preclinical pharmacokinetic showed its superior bioavailability to organs and tissues, including experimental tumor and high affinity to stomach (Zimakova et al., 2012).

Different dosage form models (fine-dispersed emulsion, liposomal dispersion, and suspension in starch paste) were investigated to determine the optimal route of cyphetrylin administration. Drug models were administrated to experimental animals with cervical cancer RShM5 in different ways, intravenous, intraperitoneal, and oral (Sof'ina et al., 1980). The results, presented in Table 1, show that the most effective route was the oral administration of cyphetrylin. Tumor growth inhibition (TGI,\%) in doses 50 and $10 \mathrm{mg} / \mathrm{kg}$ was $83 \%$ and $90 \%$, respectively, immediately after the end of treatment and therapeutically significant effect kept during 22 days. The life span of experimental mice increased by $49 \%$ and $55 \%$, respectively. Oral administration of cyphetrylin also was sufficiently effective in dose $1 \mathrm{mg} / \mathrm{kg}$ : right after the end of the administration, TGI was $73 \%$. The therapeutic effect continued for 15 days and the increase of animals' life span (ILS, \%) was 35\%.

Thus, cyphetrylin physicochemical and pharmacological properties led us to identify the tablet as the base formulation and to develop its manufacturing process. We obtained immediate release (IR) product, which contains $6 \mathrm{mg}$ of active ingredient and starch, lactose, povidone, talc, microcrystalline cellulose, calcium stearate, and magnesium stearate as excipients (Shprakh et al., 2019).The composition of cyphetrylin tablets is presented in Table 2.

To develop cyphertrylin tablets formulation and manufacturing process, which will ensure the quality, safety, and efficacy of the product, we used elements of systematic QbD approach (Claycamp et al., 2016):

- Quality target product profile (QTPP) definition.

- Critical quality attributes (CQAs) identification.

- Process/product development and initial risk assessment.

Table 2. Composition of cyphetrylin tablets.

\begin{tabular}{lccc}
\hline \multicolumn{1}{c}{ Component } & Specification & Function & $\begin{array}{c}\text { Unit } \\
\text { (mg per tablet) }\end{array}$ \\
\hline $\begin{array}{l}\text { Cyphetrylin } \\
\begin{array}{l}\text { Lactose } \\
\text { monohydrate }\end{array}\end{array}$ & In-house monograph & Active & 6 \\
$\begin{array}{l}\text { Microcrystalline } \\
\text { cellulose }\end{array}$ & PhEur & Filler & 55 \\
$\begin{array}{l}\text { Starch } \\
\text { Povidone }\end{array}$ & PhEur & $\begin{array}{c}\text { Filler/binder/ } \\
\text { disintegrant }\end{array}$ & 5 \\
$\begin{array}{l}\text { Powder blend } \\
\text { (magnesium } \\
\text { stearate, talc, and } \\
\text { starch) }\end{array}$ & PhEur & Binder & 5 \\
\hline
\end{tabular}

Table 1. Antitumor activity of cyphetrylin dosage form models by daily administration during 5 days on mice cervical cancer RShM5.

\begin{tabular}{|c|c|c|c|c|c|c|c|c|}
\hline \multirow[t]{2}{*}{ Group } & \multirow{2}{*}{$\begin{array}{l}\text { Dose, } \\
\mathrm{mg} / \mathrm{kg}\end{array}$} & \multirow{2}{*}{$\begin{array}{l}\text { Administration } \\
\text { way }\end{array}$} & \multicolumn{5}{|c|}{$\begin{array}{c}\text { TGI, } \% \\
\text { (days after the end of treatment) }\end{array}$} & \multirow{2}{*}{ ILS, \% } \\
\hline & & & 1 & $8-9$ & $15-16$ & 22 & 30 & \\
\hline \multirow{3}{*}{ Fine-dispersed emulsion } & 70 & intraperitoneal & 49 & 44 & 31 & 50 & 44 & 5 \\
\hline & 50 & \multirow{4}{*}{ intravenous } & $62 *$ & $66^{*}$ & $48^{*}$ & $52 *$ & 46 & 9 \\
\hline & 30 & & 39 & $66^{*}$ & 46 & 54 & 40 & $*$ \\
\hline \multirow{2}{*}{ Liposomal dispersion } & 40 & & $68^{*}$ & $45^{*}$ & $56^{*}$ & 45 & 47 & 0 \\
\hline & 20 & & $70^{*}$ & 39 & 34 & 24 & - & 0 \\
\hline \multirow{3}{*}{ Suspension in starch paste } & 50 & oral & $83 *$ & $80 *$ & $70 *$ & $53 *$ & - & 49 \\
\hline & 10 & $-“-$ & $90 *$ & $76^{*}$ & $67^{*}$ & $54 *$ & - & 55 \\
\hline & 1 & $-"-$ & $73 *$ & $72 *$ & $56^{*}$ & 35 & - & 35 \\
\hline
\end{tabular}

${ }^{*} p<0.05$ as related to control. 
Initially, we determined QTPP. QTPP is defined by the International Conference on Harmonization (ICH) Guideline Q8 Pharmaceutical Development as a prospective summary of the quality characteristics of a drug product that ideally will

Table 3. QTPP of cyphetrylin tablets.

\begin{tabular}{ll}
\hline QTPP attributes & QTPP \\
\hline Proposed indication & $\begin{array}{l}\text { Treatment of neuroendocrine tumors of different } \\
\text { localization (gastrointestinal tract, lung, interpleural } \\
\text { space, etc.) }\end{array}$ \\
$\begin{array}{l}\text { IR tablets without coating } \\
\text { Route of administration }\end{array}$ & Oral \\
Dosage strength & $6 \mathrm{mg}$ \\
Microbial limits & According to PhEur and PhRu current edition \\
Stability & At least 24 months shelf-life in dark place at $2^{\circ} \mathrm{C}-8^{\circ} \mathrm{C}$ \\
Container/closure system & $\begin{array}{l}\text { Plastic bottle with screw plastic cap or Alu/ } \\
\text { polyvinylchloride blister pack }\end{array}$ \\
\hline
\end{tabular}

Table 4. CQAs of cyphetrylin tablets.

\begin{tabular}{|c|c|c|c|}
\hline $\begin{array}{l}\text { Quality } \\
\text { attributes (QAs) }\end{array}$ & Target values & $\begin{array}{l}\text { Is this } \\
\text { a CQA? }\end{array}$ & Justification \\
\hline $\begin{array}{l}\text { Appearance } \\
\text { (physical } \\
\text { attributes) }\end{array}$ & $\begin{array}{l}\text { White biconvex, round } \\
\text { tablets. No visual tablet } \\
\text { defects observed }\end{array}$ & No & $\begin{array}{l}\text { Do not impact directly } \\
\text { cyphetrylin tablets safety } \\
\text { and efficacy }\end{array}$ \\
\hline Identification & Positive for cyphetrylin & Yes & $\begin{array}{l}\text { Will affect safety and } \\
\text { efficacy }\end{array}$ \\
\hline Disintegration & $\begin{array}{l}\text { Not more than } 15 \\
\text { minutes }\end{array}$ & Yes & $\begin{array}{l}\text { Will affect safety and } \\
\text { efficacy }\end{array}$ \\
\hline \multirow[t]{2}{*}{$\begin{array}{l}\text { Related } \\
\text { substances }\end{array}$} & $\begin{array}{l}\text { Any individual unknown } \\
\text { impurity: not more than } \\
1.0 \%\end{array}$ & Yes & $\begin{array}{l}\text { Will affect safety and } \\
\text { efficacy }\end{array}$ \\
\hline & $\begin{array}{l}\text { Total impurities: not } \\
\text { more than } 3.0 \%\end{array}$ & & \\
\hline $\begin{array}{l}\text { Uniformity of } \\
\text { content }\end{array}$ & Meets PhEur/PhRu & Yes & $\begin{array}{l}\text { Will affect safety and } \\
\text { efficacy }\end{array}$ \\
\hline Assay & From 5.4 to $6.6 \mathrm{mg}$ & Yes & $\begin{array}{l}\text { Will affect safety and } \\
\text { efficacy }\end{array}$ \\
\hline Microbial limits & $\begin{array}{l}\text { Meets relevant criteria of } \\
\mathrm{PhEur} / \mathrm{PhRu}\end{array}$ & Yes & $\begin{array}{l}\text { Will impact patient } \\
\text { safety }\end{array}$ \\
\hline
\end{tabular}

be achieved to ensure the desired quality, taking into account safety and efficacy of the drug product" (ICH Pharmaceutical Development Q8 (R2), 2009).

QTPP was based on our prior knowledge of the API properties, on the understanding of cyphetrylin action as SSA, and intended patient population. QTPP was formulated by especially forming an interdisciplinary team of professionals in the process and product development, manufacturing, analytical development, and quality control, regulatory, and medical professional oncologist (Konyaeva et al., 2018; Mikhaevich et al., 2011; Sanarova et al., 2016; Shprakh et al., 2019b).

Cyphetrylin tablets QTPP includes such factors as a route of administration, type of dosage form, therapeutic dose, and data on product stability and product packaging. QTPP attributes for cyphetrylin tablets are given in Table 3.
The next step after the QTPP defining and developing a lead formulation and manufacturing process was the identification of the CQAs. According to the ICH Q8, the CQA is a physical, chemical, biological, or microbiological property or characteristic that should be within an appropriate limit, range, or distribution to ensure that the desired product quality CQAs are generally associated with the drug substance, excipients, intermediates (in-process materials), and drug product" (ICH Pharmaceutical Development Q8 (R2), 2009).

CQAs have the most significant influence on QTPP and have to be controlled to ensure the desired product quality, safety, and efficacy. To identify CQAs, we reviewed the literature and the results of our past experiments (Shprakh et al., 2019).

As you can see from Table 4 data, CQAs related to product safety and efficacy are typical for tablets, correspond with PhEur (European Pharmacopoeia 9.0., 2017) and PhRu (State Pharmacopoeia of the Russian Federation, 2018) requirements to this dosage form, and are defined as follows:

- Identification

- Disintegration

- Related substances

- Content uniformity

- Assay

- Microbial limits

The next step was the estimation of each cyphetrylin tablet CQA criticality. Our interdisciplinary team assessed the degree of each CQA direct impact on the safety and/or efficacy of cyphetrylin tablets using expert questionary and according to special scales (Table 5). In such a case criticality of cyphetrylin tablets, CQAs have been counted as [impact score x uncertainty score].

It is clear that, because of the new medicine development, we had only literature data and our own in vitro/in vivo nonclinical data (Konyaeva et al., 2018; Shprakh et al., 2019), and the degree of criticality was very high. And the specialist-oncologist opinion was the deciding, and it was based on her considerable experience of another SSAs medicinal use.

From Table 6 data, it is visible that for cyphetrylin tablets "assay" and "uniformity of content" have the highest criticality, first of all, because of the minimal quantity of API in the tablet.

In the next step, we completed the manufacturing process flow diagram, which was typical for a tablet set and included the following stages:

1. Granulation (including blending, wet granulation, milling, and lubrication)

2. Compression

3. Packaging/labeling

Cyphetrylin tablets process flow diagram there is presented in Figure 1.

To determine the effects of process unit operations on final product CQAs and to identify high-risk steps, we performed a risk assessment of all stages of cyphetrylin tablets' manufacturing (ICH Pharmaceutical Quality System Q10, 2019).

ICH Q9 defines risk as "the combination of the probability of occurrence of harm and the severity of that harm" and, accordingly, risk assessment is a systematic process of 
Table 5. Scales for assessment of QAs criticality.

\begin{tabular}{lccccl}
\hline Impact & Score & Safety/efficacy changes & Uncertainty & Score & Description \\
\hline Very high & 15 & Very significant changes & Very high & 5 & No information available \\
High & 12 & Significant changes & High & 4 & Information from literature or similar products \\
Moderate & 9 & Moderate changes & Moderate & 3 & Data from nonclinical in vitro/in vivo studies \\
Low & 3 & Acceptable changes & Low & 2 & Data from clinical trials with this product \\
None & 1 & No changes & Very low & 1 & Data from medicinal use \\
\hline
\end{tabular}

Table 6. CQAs of cyphetrylin tablets $6 \mathrm{mg}$ and their relative criticality.

\begin{tabular}{lccccc}
\hline Score & Identification & Related substances & Disintegration & $\begin{array}{c}\text { Uniformity of } \\
\text { content }\end{array}$ & $\begin{array}{c}\text { Assay } \\
\text { Microbial limits }\end{array}$ \\
\hline Impact & 1 & 3 & 9 & 12 & 12 \\
Uncertainty & 3 & 3 & 3 & 3 & 3 \\
Relative criticality $^{\mathrm{a}}$ & 3 & 9 & 27 & 36 & 36 \\
\hline
\end{tabular}

aRelative criticality is impact score $\times$ uncertainty score (see Table 5 ).

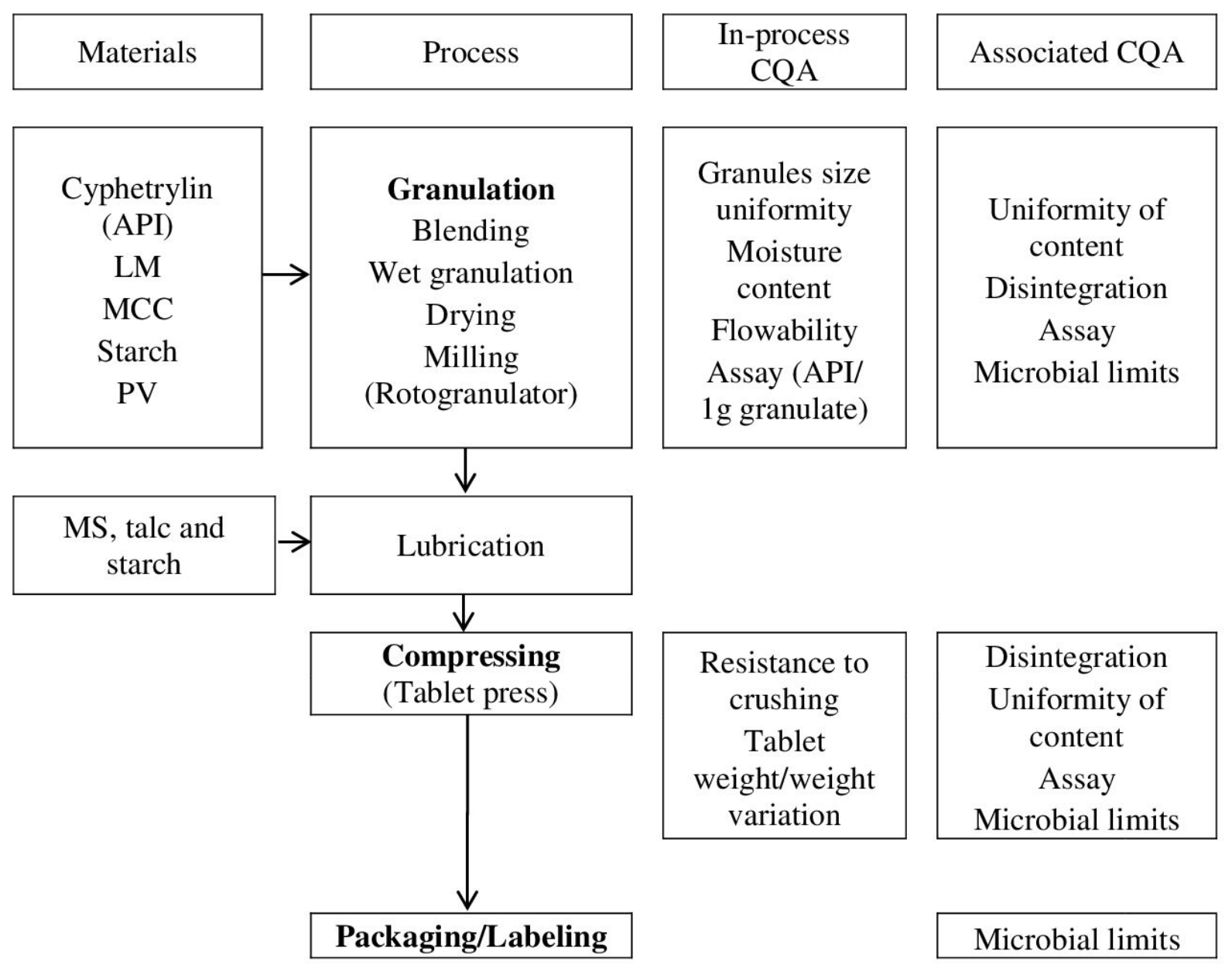

Figure 1. Cyphetrylin tablets process flow diagram. $\mathrm{LM}=$ lactose monohydrate; $\mathrm{MCC}=$ microcrystalline cellulose; Starch $=$ potato starch; $\mathrm{PV}=$ povidone; $\mathrm{MS}$ = magnesium stearate.

organizing information to support a risk decision to be made within a risk management process. It consists of the identification of hazards and the analysis and evaluation of risks associated with exposure to those hazards (ICH Quality Risk Management Q9, 2009).
For risk identification, analysis, and evaluation, we used the tool the RAMM (Brindle et al., 2012). This method allows us to estimate risk impact directly on product quality and to determine stages of the manufacturing process, which need the closest in-process quality control. 
The interdisciplinary team scored risks or impact as 9 , high; 3, moderate; and 1, minor impact on the quality attribute. In Table 7, there are results of quantitative estimation of the effects of the basic manufacturing stages on CQAs of cyphetrylin tablets, presented as a matrix.

In this case, we regard that appearance (physical attributes) is not the CQA. But this attribute is affected by manufacturing processes, which was confirmed to be acceptable during pharmaceutical development and preclinical investigation. So appearance was decided to be controlled as the in-process control.

Identification, of course, is the most significant attribute for product safety and efficacy. But it was considered as low risk of affecting QTPP: it is not affected by any manufacturing process, and the probability of the event (tablet production without API or API will be mixed up) is very low. Thus, we decided to control identification as batch release specification.
Experiments with API, including storage conditions and shelf-life research, confirmed its hydrolytic and thermal stability (Shprakh et al., 2014). During pharmaceutical development and preclinical study, no increase in related substances was seen in formulations during the manufacturing processes. Table 8 presents the data on accelerated stability studies to prove that there are no related substances originating from the interaction of API with excipients used. The results showed that the impurities' profile (any unidentified single impurity not more than $1.0 \%$ and the sum of impurities not more than $3.0 \%$ ) was stable during 3 months of observation in an accelerated storage study. And there was no appearance or disappearance of any additional peaks in the tested samples.

Analysis of UV-spectra of the API, excipients, and mixture of API and excipients also confirmed the absence of chemical interaction between API and excipients. The spirituous solution of cyphetrylin has character UV-spectrum with the

Table 7. Initial risk assessment of cyphetrylin tablets $6 \mathrm{mg}$, manufacturing process.

\begin{tabular}{|c|c|c|c|c|c|}
\hline \multirow{2}{*}{ Drug product CQA } & \multicolumn{4}{|c|}{ Manufacturing process } & \multirow{2}{*}{ Total 1} \\
\hline & Score $^{a}$ & Granulation $^{\mathrm{b}}$ & Compression & Packaging/labeling & \\
\hline $\begin{array}{l}\text { Appearance (physical } \\
\text { attributes) }\end{array}$ & 3 & 3 & 3 & 1 & 21 \\
\hline Identification & 3 & 1 & 1 & 1 & 9 \\
\hline Related substances & 9 & 1 & 1 & 1 & 27 \\
\hline Disintegration & 27 & 3 & 9 & 1 & 351 \\
\hline Uniformity of content & 36 & 9 & 9 & 1 & 684 \\
\hline Assay & 36 & 3 & 9 & 1 & 468 \\
\hline Microbial limits & 27 & 9 & 1 & 3 & 351 \\
\hline Total $2^{\mathrm{c}}$ & & 29 & 33 & 9 & \\
\hline
\end{tabular}

Total 2: sum of processes estimations.

a Score: criticality (see Table 6).

'Including blending, wet granulation, drying, milling, and lubrication; in this investigation, the processes are combined in one because all the processes are performed in rotor granulator; and after the stage completion, we have the product ready for the next stage, compression.

'Total 1: (score - criticality) $\times($ sum of each process score) .

Table 8. The results of determination of related substances in cyphetrylin tablets accelerated stability studies.

\begin{tabular}{|c|c|c|c|c|c|}
\hline \multirow{4}{*}{ Samples } & \multirow{4}{*}{ Time, months } & \multicolumn{4}{|c|}{ Related substances, \% } \\
\hline & & \multicolumn{2}{|c|}{ Any unidentified single impurity } & \multicolumn{2}{|c|}{ Sum of impurities } \\
\hline & & \multicolumn{4}{|c|}{ Limits by specification } \\
\hline & & & Not more than 1.0 & & Not more than 3.0 \\
\hline \multirow{4}{*}{010317} & 0 & $0.62 \pm 0.01$ & $0.91 \pm 0.03$ & $1.04 \pm 0.04$ & $2.57 \pm 0.06$ \\
\hline & 1 & $0.56 \pm 0.01$ & $0.93 \pm 0.04$ & $1.03 \pm 0.04$ & $2.52 \pm 0.05$ \\
\hline & 2 & $0.64 \pm 0.02$ & $0.93 \pm 0.04$ & $1.07 \pm 0.05$ & $2.64 \pm 0.05$ \\
\hline & 3 & $0.62 \pm 0.02$ & $0.85 \pm 0.02$ & $1.09 \pm 0.04$ & $2.56 \pm 0.04$ \\
\hline \multirow{4}{*}{031117} & 0 & $0.83 \pm 0.03$ & $0.93 \pm 0.03$ & $1.07 \pm 0.05$ & $2.83 \pm 0.06$ \\
\hline & 6 & $0.80 \pm 0.02$ & $0.87 \pm 0.03$ & $1.13 \pm 0.05$ & $2.80 \pm 0.05$ \\
\hline & 2 & $0.82 \pm 0.03$ & $0.92 \pm 0.04$ & $1.02 \pm 0.04$ & $2.76 \pm 0.06$ \\
\hline & 3 & $0.83 \pm 0.03$ & $0.95 \pm 0.04$ & $1.05 \pm 0.04$ & $2.83 \pm 0.05$ \\
\hline \multirow{4}{*}{030318} & 0 & $0.73 \pm 0.02$ & $0.91 \pm 0.03$ & $0.95 \pm 0.02$ & $2.59 \pm 0.06$ \\
\hline & 1 & $0.72 \pm 0.02$ & $0.82 \pm 0.03$ & $0.99 \pm 0.04$ & $2.53 \pm 0.06$ \\
\hline & 2 & $0.84 \pm 0.03$ & $0.84 \pm 0.01$ & $0.91 \pm 0.04$ & $2.59 \pm 0.05$ \\
\hline & 3 & $0.72 \pm 0.02$ & $0.93 \pm 0.04$ & $0.94 \pm 0.03$ & $2.59 \pm 0.06$ \\
\hline
\end{tabular}

All values are reported as mean $\pm \mathrm{SD}, n=6$ measurements. 
maxima of absorbance at wavelengths $(274 \pm 2 \mathrm{~nm}, 282 \pm 2 \mathrm{~nm}$, and $290 \pm 4 \mathrm{~nm}$ ). In Figure 2A, it is quite evident that excipients did not influence spectral characters of cyphetrylin. The positions of absorption bands maxima and intensity of absorbance were stable during accelerated stability studies (Fig. 2B).

So it was considered that the content of related substances (product-related impurities and products of API-excipients interactions) has a low risk of affecting efficacy and safety in patients, provided that the impurities in the drug substance and excipients within the specifications.

Evaluation of cyphetrylin tablets process flow diagram (Fig. 1) and results of initial risk assessment, presented in Table 9, confirmed the high-risk CQAs, in-process CQAs, and manufacturing processes, which have a significant effect on them:

- Disintegration is affected by compressing (resistance to crushing; moisture content).

- Uniformity of content is influenced by granulation (blend uniformity; granule size uniformity) and compressing (tablet weight/weight variation).

- Assay (the content of cyphetrylin) is considered high risk because it is affected by compressing (weight/weight variation).

- Microbial limits are affected by all stages of the manufacturing process. It is guaranteed on the one hand by facility, processes, and raw materials and production scale compliance with the relevant requirement on microbial purity, but on the other hand because of wet granulation method use by continuous monitoring of moisture content during the manufacturing process.

For the implementation of risk assessment, the relationship between QTPP, CQA, and in-process CQAs is shown in Figure 3 in the form of Ishikawa fishbone diagram.

In the initial risk, assessment of the manufacturing process also used FMEA method (Inoue and Yamada, 2010) to estimate each potential failure effect according to its severity, probability, and detectability. Failure risks were calculated by Risk Priority Number (RPNs) = Severity x Probability x Detectability. The severity was a measure of how severe the effect failure mode would be; by the probability of occurrence, we meant the likelihood of an event occurring: 5, for event likely to happen; 3 , a chance of occurring will be $50-50 ; 1$, unlikely to occur; and detectability was 1 for easy detectable; 3 , for moderate detectable; and 5 , as hard to detect. Using this procedure, we created the ranking shown in Table 9.

The in-process CQAs and limits for their control in the manufacturing process are presented in Table 10. All procedures were performed according to the current edition of PhEur and PhRu (European Pharmacopoeia 9.0., 2017, State Pharmacopoeia of the Russian Federation, 2018). It has been established that moisture content (loss on drying) has the most significant effect on granulate flowability and cyphetrylin tablets' technical characteristics. It has been shown that increasing residual moisture content higher than $4.0 \%$ leads to loss of granulate
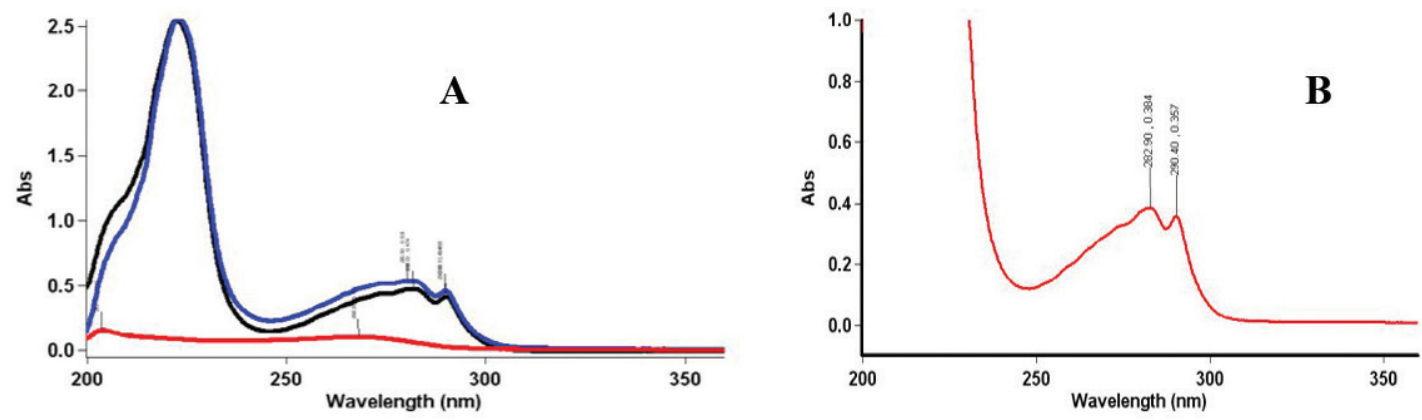

Figure 2. UV-spectra of spirituous solutions of - cyphetrylin, — excipients, and - the mixture of cyphetrylin and excipients (A); cyphetrylin tablets in accelerated stability studies [3 months of storage at $40^{\circ} \pm 2^{\circ} \mathrm{C}$ and $\mathrm{RH} 75 \pm 5 \%$ (B)].

Table 9. Results of FMEA risk assessment for cyphetrylin manufacturing process.

\begin{tabular}{|c|c|c|c|c|c|c|}
\hline CQA & Potential failure mode & Effect & Severity & Probability & Detectability & $\mathbf{R P N}^{\mathrm{a}}$ \\
\hline \multirow[t]{2}{*}{ Disintegration } & Moisture content & Change in disintegration & 3 & 4 & 3 & 36 \\
\hline & Resistance to crushing & Change in disintegration & 3 & 4 & 2 & 36 \\
\hline \multirow[t]{3}{*}{ Uniformity of content } & Blend uniformity & Not uniform & 4 & 4 & 2 & 32 \\
\hline & Granule size uniformity & Not uniform & 4 & 4 & 2 & 32 \\
\hline & $\begin{array}{l}\text { Tablet weight/tablet } \\
\text { weight variation }\end{array}$ & Not uniform & 4 & 4 & 3 & 48 \\
\hline Assay (cyphetrylin content) & $\begin{array}{l}\text { Tablet weight/tablet } \\
\text { weight variation }\end{array}$ & Change in content & 4 & 4 & 2 & 32 \\
\hline Microbial limits & Moisture content & Microbial contamination & 3 & 3 & 3 & 27 \\
\hline
\end{tabular}

${ }^{a} \mathrm{RPN}$ is $\geq 40$ (high risk), $\geq 20$ and $<40$ (medium risk), and $<20$ (low risk). 


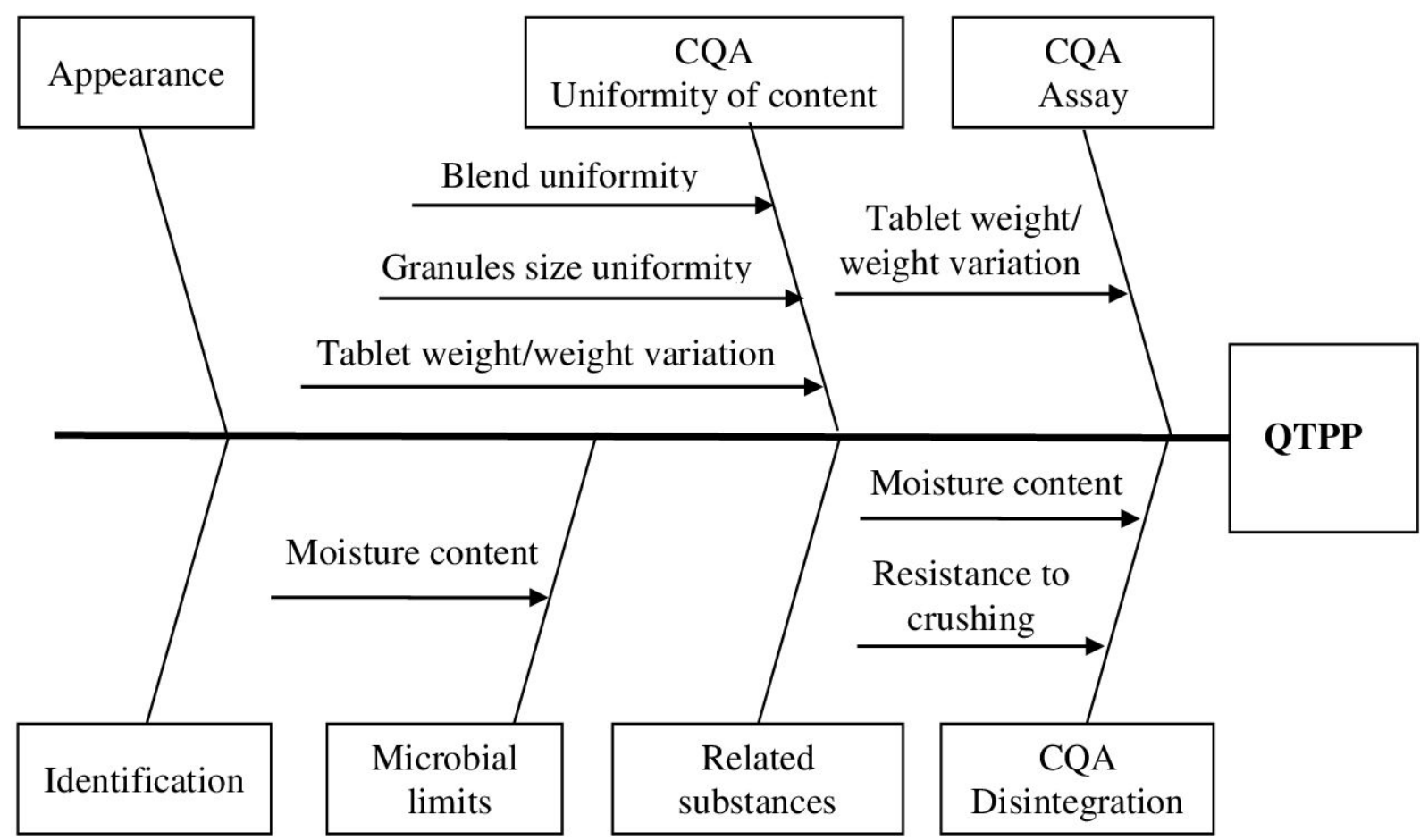

Figure 3. Relationship between QTPP, CQA, and in-process CQA.

Table 10. In-process CQAs and their limits in the manufacturing process.

\begin{tabular}{lll}
\hline Process & In-process CQA & Limits \\
\hline Granulation & Granule size uniformity & Not more than $1 \mathrm{~mm}$ \\
& Flowability & $6.2-6.6 \mathrm{~g} / \mathrm{s}$ \\
& Moisture content (loss on drying) & Not more than $4.0 \%$ \\
Compression & Resistance to crushing & Not less than $30 \mathrm{~kg} \cdot \mathrm{m} \cdot \mathrm{s}^{-2}$ \\
& Tablet weight/weight variation & From 95 to $116 \mathrm{mg} ; \pm 7.5 \%$ \\
\hline
\end{tabular}

Table 11. Influence of granulate moisture content (loss on drying) on its flowability and technical characteristics of cyphetrylin tablets.

\begin{tabular}{|c|c|c|c|}
\hline \multicolumn{2}{|c|}{ Granulate character } & \multicolumn{2}{|c|}{ Tablet character } \\
\hline Loss on drying, $\%$ & Flowability, $\mathrm{g} / \mathrm{s}$ & Resistance to crushing, $\mathrm{kg} \cdot \mathrm{m} \cdot \mathrm{s}^{-2}$ & Tablets disintegration, minute \\
\hline $4.21 \pm 0.92$ & $3.23 \pm 0.29$ & $44.80 \pm 3.25$ & $14 \pm 2$ \\
\hline $3.87 \pm 0.56$ & $6.23 \pm 0.33$ & $39.62 \pm 5.11$ & $9 \pm 1$ \\
\hline $2.78 \pm 0.68$ & $6.48 \pm 0.24$ & $36.21 \pm 7.52$ & $9 \pm 3$ \\
\hline $1.91 \pm 0.48$ & $6.24 \pm 0.18$ & $34.18 \pm 6.21$ & $13 \pm 4$ \\
\hline $1.59 \pm 0.32$ & $6.38 \pm 0.19$ & $34.01 \pm 3.25$ & $14 \pm 3$ \\
\hline
\end{tabular}

Data are represented as mean $\pm \mathrm{SD}, n=3$ measurements. ${ }^{\mathrm{a}} n=6$.

flowability and its binding on tablet punch tooling. Resistance to crushing of tablets, obtained from such granulate, did not increase significantly (Table 11).

\section{CONCLUSION}

In this study, we applied elements of QbD approach developing tablets of SSA cyphetrylin. We have defined the CQAs and estimated their criticality, showing that assay and uniformity of content are the most critical because of the minimal quantity of API in tablets. Initial risk assessment of cyphetrylin tablets' manufacturing process indicated that the granulation and compression stages are the riskiest and strongly influence all CQAs. It has been estimated that the moisture content of granulate is the most critical in-process CQA which affects pharmacotechnological characters of cyphetrylin granulate and tablets and their microbial limits. 


\section{ACKNOWLEDGMENTS}

This work was funded by the Russian Ministry of Industry and Trade (Grant no. 11411.0008700.13.082).

\section{AUTHOR CONTRIBUTIONS}

All authors made substantial contributions to conception and design, acquisition of data, or analysis and interpretation of data; took part in drafting the article or revising it critically for important intellectual content; agreed to submit to the current journal; gave final approval of the version to be published; and agree to be accountable for all aspects of the work. All the authors are eligible to be an author as per the international committee of medical journal editors (ICMJE) requirements/guidelines.

\section{CONFLICTS OF INTEREST}

The authors report no financial or any other conflicts of interest in this work.

\section{ETHICAL APPROVALS}

This study does not involve experiments on animals or human subjects.

\section{PUBLISHER'S NOTE}

This journal remains neutral with regard to jurisdictional claims in published institutional affiliation.

\section{REFERENCES}

Anthony L, Freda PU. From somatostatin to octreotide LAR: evolution of a somatostatin analogue. Curr Med Res Opin, 2009; 25(12):2989-99.

Bak A, Leung D, Barrett SE, Forster S, Minnihan EC, Leithead AW, Cunningham J, Toussaint N, Crocker LS. Physicochemical and formulation developability assessment for therapeutic peptide delivery - a primer. AAPS J, 2015; 17(1):144-55.

Borisova LM, Kiseleva MP, Osipov VN, Sushinina LP, Ustinkina SV, Smirnova LI, Shprakh ZS. Cyphetrylin cytotoxic analogues (report II). Russ J Biother, 2017; 16(2):23-9.

Bousquet C, Lasfargues C, Chalabi M, Billah CM, Susini C, Vezzosi D, Caron P, Pyronnet S. Clinical review: current scientific rationale for the use of somatostatin analogs and mTOR inhibitors in neuroendocrine tumor therapy. J Clin Endocrinol Metab, 2012; 97(3):727-37

Brindle A, Davy S, Tiffany D, Watts Ch. Risk analysis and mitigation matrix (RAMM) - a risk tool for quality management. Pharm Eng, 2012; 32(1):1-7.

Claycamp HG, Kona R, Fahmy R, Hoag SW. Quality-bydesign II: application of quantitative risk analysis to the formulation of ciprofloxacin tablets. AAPS PharmSciTech, 2016; 17(2):233-44.

Dasari A, Shen C, Halperin D, Zhao B, Zhou S, Xu Y, Shih T, Yao JC. Trends in the incidence, prevalence, and survival outcomes in patients with neuroendocrine tumors in the United States. JAMA Oncol, 2017; 3(10):1335-42.

Directive 2004/9/EC. European Parliament and of the Council of 11 February 2004 on the inspection and verification of good laboratory practice (GLP). 2004. Available via https://eur-lex.europa.eu (Accessed 16 September 2019)

European Pharmacopoeia 9.0. Strasbourg: council of Europe; European Pharmacopoeia 9.0, Strasbourg, France, 2017.

Gobeaux F, Fay N, Tarabout C, Mériadec C, Meneau F, Ligeti M, Buisson DA, Cintrat JC, Nguyen KM, Perrin L, Valéry C, Artzner F, Paternostre M. Structural role of counterions adsorbed on self-assembled peptide nanotubes. J Am Chem Soc, 2012; 134(1):723-33.
Gugger M, Waser B, Kappeler A, Schonbrunn A, Reubi JC. Cellular detection of sst2A receptors in human gastrointestinal tissue. Gut, 2004; 53(10): 1431-6.

ICH Pharmaceutical Development Q8 (R2). Part I: pharmaceutical development and part II: annex to pharmaceutical development. [Electronic source], 2009. Available via: https://www.ich. org (Accessed 16 September 2019).

ICH Pharmaceutical Quality System Q10. [Electronic source], 2009. Available via https://www.ich.org (Accessed 16 September 2019).

ICH Quality risk management Q9. [Electronic source], 2009. Available via: https://www.ich.org (Accessed 16 September 2019).

Inoue $\mathrm{H}$, Yamada $\mathrm{S}$. Failure mode and effects analysis in pharmaceutical research. Int J Qual Serv Scie, 2010, 2(3):369-82.

Konyaeva OI, Kulbachevskaya NYu, Ermakova NP, Chaley VA, Merkulova IB, Abramova TV, Buchman VM, Shprakh ZS. Preclinical toxicological study of analogue of hypothalamic hormone cyphetrylin. Russ J Biother, 2018; 17(2):63-70.

Mikhaevich EI, Krasil'nikov MA. The mechanism of cytostatic effect of a new somatostatin analog cifetrelin on In vitro cultured MCF7 breast carcinoma cells. Bull Exp Biol Med, 2013; 154(5):669-72; doi:10.1007/s10517-013-2026-3.

Mikhaevich EI, Yavorskaya NP, Golubeva IS, Oborotova NA, Alyautdin RN. Antitumor effect of the somatostatin analogue cyphetrylin in vivo. Probl Biol Med Pharm Chem, 2011; 10:68-72.

Oberg K, Kvols L, Caplin M, Delle Fave G, de Herder W, Rind G, Ruszniewski P, Woltering EA, Wiedenmann B. Consensus report on the use of somatostatin analogs for the management of neuroendocrine tumors of the gastroenteropancreatic system. Ann Oncol, 2004; 15:966-73.

Osipov VN, Sushinina LP, Ustinkina SV, Smirnova LI, Shprakh ZS.Cyphetrylin cytotoxic analogues (report I). Russ J Biother, 2016; 15(4):85-8.

Sanarova EV, Lantsova AV, Mikhaevich EI, Shprakh ZS, Smirnova LI, Yavorskaya NP, Oborotova NA. The prospect of the creation of a dosage form of domestic analogue of hypothalamic hormone somatostatin in the treatment of hormone-dependent tumors. Russ J Biopharm, 2016; $8(2): 14-9$.

Shaji J, Patole V. Protein and peptide drug delivery: ora approaches. Indian J Pharm Sci, 2008; 70(3):269-77.

Shprakh Z. Somatostatin analogues for the treatment of neuroendocrine tumors. dosage forms and routes of administration (Review). Int J Appl Pharm, 2020; 12(2):6-11.

Shprakh Z, Borisova LM, Kiseleva MP, Smirnova ZS Preclinica study of cyphetrylin antitumor efficiency on experimental animal tumors. Exp Clin Pharmacol, 2019; 82(8):27-31.

Shprakh ZS, Ignatieva EV, Yartseva IV, Dmitricheva NA, Smirnova LI. Development and validation of cyphetrylin assay in tablets. Russ J Biother, 2016; 15(3):55-61.

Shprakh Z, Orlova O, Ignatieva E, Oborotova N, Bunyatyan N. Formulation and evaluation of somatostatin analogue tablets. Int J Appl Pharm, 2019; 11(4):220-3.

Shprakh ZS, Yartseva IV, Ignateva EV, Smirnova AP, Sushinina LP, Ustinkina SV, Smirnova LI, Budko AP, Zimakova NI. Synthesis and chemico-pharmaceutical characteristics of somatostatin analog with antitumor activity. Pharm Chem J, 2014; 3:159-62.

Smirnova LI, Ustinkina SV, Orlova OL, Oborotova NA, Smirnova ZS, Kubasova IYU, Shprakh ZS. Drug substance with antitumour action. Patent Ru 2254139, 2005.

Sof'ina ZP, Syrkin AB, Goldin A., Klein A. Experimental evaluation of antitumor drugs in USSR and USA. Medicine, Moscow, Russia, 1980

State Pharmacopoeia of the Russian Federation", 14 Ed., 2018. The Ministry of Health of the Russian Federation, Moscow, Russia, 2018.

Thanou M, Verhoef JC, Verheijden JH, Junginger HE. Intestinal absorption of octreotide using trimethylchitosan chloride: studies in pigs. Pharm Res, 2001; 18(6):823-8. 
Thundimadathil J. Cancer treatment using peptides: current therapies and future prospects. J Amino Acids. 2012; 2012:967347.

Tiberg F, Roberts J, Cervin C, Johnsson M, Sarp S, Tripathi AP, Linden M. Octreotide s.c. depot provides sustained octreotide bioavailability and similar IGF-1 suppression to octreotide LAR in healthy volunteers. $\mathrm{Br}$ J Clin Pharmacol, 2015; 80(3):460-72.

Yao JC, Lagunes DR, Kulke MH. Targeted therapies in neuroendocrine tumors (NET): clinical trial challenges and lessons learned. Oncologist, 2013; 18(5):525-32.

Zimakova NI, Kolesnikova EY, Budko AP, Deychman ZG, Zolotarev AE, Badun GA, Chernysheva MG. Preclinical study pharmacokinetics drug form of analog hypothalamic hormone somatostatine (AGG). Russ J Biother, 2012; 11(3):33-8.

\section{How to cite this article:}

Shprakh Z. Formulation of somatostatin analog tablets using quality by design approach. J Appl Pharm Sci, 2021; 11(04):096-105. 